BULLETIN Bulletin hispanique

HISPANIQUE Université Michel de Montaigne Bordeaux

116-2 | 2014

Référentialité/autoréférentialité dans le roman

espagnol contemporain : bilan et perspectives

\title{
Jacinto Luis Guereña, Corazón de miedo y de sueños.
} Antología (1946-2001)

Renacimiento, Sevilla, 2013

Jacques Issorel

\section{OpenEdition \\ Journals}

\section{Édition électronique}

URL : http://journals.openedition.org/bulletinhispanique/3679

DOI : 10.4000/bulletinhispanique.3679

ISBN : 979-10-300-0156-3

ISSN : $1775-3821$

Éditeur

Presses universitaires de Bordeaux

Édition imprimée

Date de publication : 1 décembre 2014

Pagination : 927-929

ISBN : 978-2-86781-963-6

ISSN : 0007-4640

Référence électronique

Jacques Issorel, « Jacinto Luis Guereña, Corazón de miedo y de sueños. Antología (1946-2001) », Bulletin hispanique [En ligne], 116-2 | 2014, mis en ligne le 01 décembre 2017, consulté le 23 septembre 2020. URL : http://journals.openedition.org/bulletinhispanique/3679; DOI : https://doi.org/10.4000/ bulletinhispanique.3679

Ce document a été généré automatiquement le 23 septembre 2020.

Tous droits réservés 


\title{
Jacinto Luis Guereña, Corazón de miedo y de sueños. Antología (1946-2001)
}

\author{
Renacimiento, Sevilla, 2013
}

Jacques Issorel

\section{RÉFÉRENCE}

Jacinto Luis Guereña, Corazón de miedo y de sueños. Antología (1946-2001), edición y estudio introductorio a cargo de Jean-Louis Guereña y Claude Le Bigot, Sevilla, Renacimiento, 2013, 446 p., 1 ill.

Né en 1915 en Argentine d'un père basque et d'une mère d'origine italienne, Jacinto Luis Guereña passe son enfance au Maroc avant d'aller en 1932 à Madrid, où il est admis au concours d'entrée à l'Escuela Normal de Magisterio Primario. Il ne tarde pas à s'engager dans les rangs de la F. U. E. (Federación Universitaria Escolar) et à militer en contact étroit avec les Jeunesses socialistes et communistes. De cette même époque date son éveil à ce qui sera une vocation autant qu'une raison de vivre : la création poétique et l'amour de la littérature ( $Y$ Yo ya me creía poeta, escribía poemas, leía muchísimos libros de poesía. Y revistas literarias", p. 40). Il publie ses premiers poèmes à vingt ans, fréquente le café Pombo, où il connaît André Breton et Paul Éluard, et a le privilège de converser avec Federico García Lorca, Rafael Alberti et Alejandro Casona à la Residencia de Estudiantes. Quand, en juin 1936, il achève brillamment ses études à l'École normale et se prépare à commencer son stage pédagogique avec la perspective d'un salaire le mettant définitivement à l'abri du besoin, Jacinto Luis Guereña a devant lui un «porvenir profesional [...] ya perfectamente diseñado y risueño» (p. 44). Comme des milliers de jeunes Espagnols qui, une fois leurs études terminées, s'apprêtent à entrer dans la vie active, Jacinto Luis Guereña voit subitement ses espoirs s'effondrer, le 18 juillet 1936. Son père (qui connaîtra les geôles franquistes en 1939) et lui s'engagent aussitôt dans les Milicias 
Vascas Antifranquistas et, en octobre de cette même année, le jeune Jacinto Luis est incorporé comme «soldado del nuevo Ejército Popular de la República» (p. 47), ce qui ne l'empêche pas de continuer à œuvrer pour la culture au sein des Milicias de la Cultura, où il apporte, en compagnie d'autres instituteurs, «una enseñanza de tipo elemental a los combatientes necesitados de ella»(ibid.). Malgré les vicissitudes de la guerre et les déplacements, il lit beaucoup, écrit et publie même des poèmes dans d'éphémères revues heureusement retrouvées par Serge Salaün. Après la bataille de l'Èbre (été 1938), dont il gardera toute sa vie le souvenir atroce, et la chute de Barcelone, le 26 janvier 1939, Jacinto Luis Guereña se voit contraint à l'exil. On sait ce que fut l'accueil en France de ces centaines de milliers de républicains espagnols: les camps de concentration sur les plages du Roussillon, le froid, les conditions d'hygiène déplorables. Guereña connaît surtout le camp de Gurs (Pyrénées-Atlantiques) dont il sort en novembre 1939. À partir de ce moment, il survit en travaillant comme bûcheron ou charbonnier, puis comme lecteur à l'École normale de Lescar, près de Pau. Loin de se laisser abattre par l'adversité, le jeune exilé s'engage résolument dans une deuxième vie en terre étrangère. Lui qui avait rêvé d'être un poète espagnol se veut maintenant poète espagnol et français et, à cet effet, «se impo[ne] a sí mismo conocer a fondo todas las sutilezas del idioma galo» (p.63). Bien que dépourvu de moyens, il crée, en 1945, une revue, Méduse, qu'il conçoit comme un organe du «Frente franco-español de las letras». C'est à cette même époque que voient le jour ses premières plaquettes en langue française : L'homme, l'arbre, l'eau (1944) et Ode pour la grande naissance du jour (1945). Comme il ne cessera de le faire tout au long de sa vie, il publie, soit en espagnol, soit en français, des poèmes dans des revues et aussi des traductions et des articles de critique littéraire. Son refus, jusqu'à sa mort jamais démenti, de demander la nationalité française, l'empêche d'exercer autrement qu'en qualité de lecteur, d'abord à Lescar, ensuite à Toulon, où il obtient, en 1959, un poste qu'il conservera jusqu'à sa retraite en 1980. Grâce aux contacts qu'il a établis avec le monde universitaire et le monde de la culture en général, il est souvent invité à donner des conférences dans les universités ou ailleurs et même à dispenser des cours à la prestigieuse École normale supérieure de Saint-Cloud. À partir de 1965, il retourne régulièrement en Espagne, y fait même de longs séjours au cours desquels il se lie d'amitié avec plusieurs grands noms de la littérature espagnole, tels que Vicente Aleixandre et Luis Rosales. En ces temps où la poésie, et même le nom, de Miguel Hernández «eran aún algo sulfuroso para el régimen franquista» (p. 79), Jacinto Luis Guereña publie chez Taurus une anthologie du poète (1967), comme il l'avait fait trois ans auparavant chez Seghers dans la fameuse collection « Poètes d'aujourd'hui ». Deux autres ouvrages : une étude (Narcea, 1973) et une biographie illustrée (Destino, 1978), témoignent aussi de son attachement au poète d'Orihuela. Parallèlement, entre 1971 et 2001, il écrit et publie en Espagne pas moins de quatorze recueils de poésie en langue espagnole. Il y a alors chez lui une soif de reconnaissance, la volonté de refermer la longue parenthèse de silence imposée par l'exil. En effet, de 1946, année où il publie en France la plaquette, au titre éloquent de Poema del dolor y de la sonrisa de España, à 1971, année où voit le jour Noticias, le premier recueil de la série de quatorze signalée plus haut, Jacinto Luis Guereña n'a rien publié en Espagne. La poésie qu'il continue néanmoins d'écrire en français (sept plaquettes, entre 1953 et 1992) qu'accueillent des revues telles qu'Europe et La Nouvelle Revue Française, lui vaut de figurer non seulement dans nombre d'anthologies (celles de Serge Brindeau et de Robert Sabatier, entre autres), mais aussi dans le Dictionnaire de la poésie française contemporaine de Jean Rousselot (1968). «Escritor bilingüe par la force des choses 
", comme le définit son fils Jean-Louis, auteur de la très documentée et passionnante " Semblanza de un itinerario intelectual y humano» (p. 9-95), très sommairement résumée dans les lignes qui précèdent, anticonformiste, antimonarchiste, Jacinto Luis Guereña fut avant tout un poète et un homme jusqu'au bout «fiel a sus compromisos iniciales» (p. 94).

2 Mort à Madrid en 2007, il a laissé une œuvre poétique en espagnol considérable et surtout originale, comme s'applique à le montrer Claude Le Bigot, dans «Perfil de un exilio poético», deuxième partie de l'introduction (p. 97-132). Le Bigot observe chez le poète une «tendencia enumerativa» (p.106), elle-même conséquence de l'«existencia dispersa» que l'exil lui a imposée. Cette tendance s'exprime à travers une double modalité : l'absence de titre des poèmes (un simple numéro en tient lieu) et leur autonomie, qui, ajoutées à l'usage fréquent de la parataxe et à l'élimination des verbes, induisent un «discurso sin temporalidad» (p. 107). Celui-ci offre la vision d'un monde fragmenté, «de una existencia sin perspectivas», et cependant le chant de Guereña est loin d'être désespéré. Sa confiance dans le langage, son espérance («Podéis abatir el árbol: / retoñarán las raíces [...] nunca serán cenizas / las alas de la vida", «Proyección de hombre y tierra», p. 217), sa quête de l'humain, dessinent, recueil après recueil, une «conciencia plural» («Soledades mías / bajo el nombre de pluralidad», "Esta fuente de poemas», cité p. 106). De même, dans le recueil au titre lorquien et évocateur de Como un río de recuerdos (1976), Guereña affirme sa solidarité avec tous les exilés, ceux de l'extérieur et ceux de l'intérieur. Homme de deux pays, de deux cultures, il n'a cessé dans sa bilingue création poétique de recomposer un univers fragmenté ou, comme l'écrit élégamment Claude Le Bigot, d'«acot[ar] un territorio de tránsito -el de la poesía- para suturar las separaciones o las cicatrices debidas a la Historia» (p.112). Il en résulte, ajoute le critique, une tension constamment repérable entre les contraires : visible/invisible, ici/là-bas, connu/inconnu. C'est bien là un des traits majeurs de la poésie de Jacinto Luis Guereña : ne jamais offrir l'image d'une harmonie réalisée, toujours celle d'un monde à l'œuvre.

Un portrait au crayon du poète par Ramón Lapayese, particulièrement ressemblant et expressif, une bibliographie de l'œuvre poétique d'expression espagnole et française, ainsi que quelque trois cents notes très fournies, qui par leur précision constituent une mine bibliographique, complètent la partie introductive. L'anthologie recueille plus de deux cents poèmes (p. 139-403). Le lecteur aura le bonheur d'y découvrir (ou d'y retrouver) une poésie où «lo sensible prima sobre lo racional» (Le Bigot, p. 99), ou, comme l'a écrit Enrique Montero, une «poesía intimista [que] recoge la tradición de la mejor poesía del 27, pero que a la vez tiene una veta de los clásicos conceptistas españoles» (cité p. 83).

\section{AUTEURS}

JACQUES ISSOREL

Université de Perpignan 